\title{
Saúde do trabalhador e economia solidária: estudo de uma cooperativa de construção civil
}

\author{
Scheila Girelli, ^ Márcia Luiza Pit Dal Magro \\ Universidade Comunitária da Região de Chapecó, Chapecó, SC, Brasil
}

Resumo

\begin{abstract}
Este trabalho propõe-se discutir o potencial da Economia Solidária para o campo da saúde do trabalhador. Trata-se de uma pesquisa qualitativa que teve como objetivo analisar as vivências de prazer e sofrimento no trabalho de operários da construção civil inseridos em um empreendimento de Economia Solidária. Foram utilizados como procedimentos e técnicas de pesquisa a observação, questionário e grupo focal. A análise das informações foi embasada na perspectiva teórica da Psicodinâmica do Trabalho. Os resultados apontam para a prevalência de vivências de prazer no contexto trabalho estudado, relacionadas à presença dos principios da Economia Solidária e do cooperativismo. Contudo, emergem também vivências de sofrimento, especialmente relacionadas aos riscos do trabalho e aos danos físicos ocasionados por esse. Assim, antigos problemas do setor da construção civil se reproduzem nesse contexto, como a presença de acidentes de trabalho, recusa no uso de EPIs e estratégias defensivas para negar os riscos.
\end{abstract}

Palavras-chave: saúde do trabalhador; economia solidária; construção civil; psicodinâmica do trabalho.

\section{Worker health and solidarity economy: study of a construction cooperative}

\begin{abstract}
This study proposes to discuss the potential of the Solidarity Economy to the occupational health field. This is a qualitative research that aimed to analyze the experiences of pleasure and pain at work of construction workers inserted in a venture of Solidarity Economy. Observation, questionnaire and focus group were used as research techniques and procedures. The analysis of information was based on the theoretical perspective of Work Psychodynamic. The results point to the prevalence of experiences of pleasure in the studied work context, related to the presence of the principles of solidarity economy and cooperativism. However, distress experiences also emerge, especially related to the risks of the job and the physical damage caused by that. Thus old problems of the construction industry are reproduced in this context, as the presence of accidents at work, refusals to wear the PPE (personal protective equipment) and defensive strategies to negate the risks.
\end{abstract}

Keywords: occupational health, solidarity economy; construction; work psychodynamic.

\section{Introdução}

A sociedade do século XX protagonizou um intenso processo de industrialização, caracterizado pelo acelerado avanço tecnológico, pelas crises econômicas e pelas mudanças nos modelos de gestão, aspectos que imprimiram novos modos de organização ao trabalho. A herança dessas transformações para a sociedade atual inclui, de acordo com Silva (2012), aspectos como a flexibilização e a intensificação do trabalho, salários rebaixados e irregulares e o enfraquecimento da organização da classe trabalhadora.

As problemáticas que compõe o atual "mundo do trabalho" exercem diversos impactos na saúde dos trabalhadores, ajudando a produzir, de acordo com Karam (2008), "sintomas psicossociais". Como representantes desses se pode citar o aumento nos acidentes e nas doenças relacionadas ao trabalho com destaque para os transtornos mentais e comportamentais e as Lesões por Esforços Repetitivos/Distúrbios Osteo musculares Relacionados ao Trabalho (LER/DORT), como expressam os dados do INSS analisados por Todeschini e Lino (2010).

As dificuldades do contexto atual dão origem a inúmeras formas de organização social que visam atender as necessidades e os anseios da população em geral e da

\footnotetext{
^Endereço para correspondência: Universidade Comunitária da Região de Chapecó, Unochapeco. Avenida Senador Atilio Fontana, 591-E - Efapi. Chapecó, SC - Brasil. CEP: 89809000. Caixa-postal: 1141.E-mail: scheilapsi@unochapeco.edu.br, mapit@unochapeco.edu.br
}

classe trabalhadora em particular. Entre essas organizações sociais, tem destaque a Economia Solidária (ES), que, por meio da articulação de diversos atores, propõe alternativas aos problemas gerados pelo atual sistema econômico com iniciativas associativas e solidárias voltadas à reprodução da vida. Sob a orientação de um conjunto de princípios, como solidariedade, igualdade, desenvolvimento local e preservação ambiental, a ES se propõe a apontar para mudanças estruturais no modelo econômico, rompendo com processos de trabalho centrados no lucro e no acúmulo indiscriminado.

Para Singer (2002), a definição da economia solidária está ligada à negação da separação entre trabalho e posse dos meios de produção, que é reconhecidamente a base do capitalismo. Ou seja, "[...] a empresa solidária é basicamente de trabalhadores, que apenas secundariamente são seus proprietários. Por isso, sua finalidade básica não é maximizar lucro, mas a quantidade e a qualidade do trabalho" (SINGER, 2002, p. 84).

A Economia Solidária é entendida como um movimento que compreende uma diversidade de ações e de formas de produção associativas, envolvendo desde iniciativas locais, tais como os empreendimentos solidários, até propostas mais globais de coordenação econômica e jurídica, tendo no cooperativismo sua principal expressão (QUIJANO, 2002). Os empreendimentos solidários têm 
se constituído como formas alternativas de geração de trabalho e de renda para segmentos excluídos da população brasileira. $\mathrm{O}$ cooperativismo traz princípios importantes para a constituição desses empreendimentos, entre os quais se destacam o controle democrático por parte dos membros, o compromisso com a educação dos mesmos e a contribuição para o desenvolvimento da comunidade em que está localizado (BIRCHALL, 1997 apud SANTOS; RODRÍGUEZ, 2002). Assim, esses empreendimentos são fundamentalmente organizações dentro das quais se esperam relações humanas muito diversas daquelas promovidas por organizações de trabalho tradicionais, ou seja, em que o valor central seja o bem-estar do sujeito, em contraponto a acumulação privada de riquezas.

No Brasil, os empreendimentos solidários ganham visibilidade a partir da década de 1990, crescendo, desde então, em larga proporção. Dados da Secretaria Nacional de Economia Solidária (BRASIL, 2013) ${ }^{1}$ apontam que existem aproximadamente 20 mil empreendimentos de ES mapeados em todo País, envolvendo, aproximadamente, 1,4 milhão de trabalhadores. Desses empreendimentos, 38 são da construção civil, dos quais três localizam-se no Estado de Santa Catarina, sendo um destes o locus deste estudo.

No contexto apontado anteriormente, as universidades têm sido agentes importantes no fomento de empreendimentos solidários, por meio das Incubadoras Tecnológicas de Cooperativas Populares (ITCPs). A inserção em empreendimentos de ES vinculados a uma dessas incubadoras despertou-nos o interesse em compreender como se dá a organização do trabalho nesses coletivos e sua relação com as vivências de prazer e sofrimento dos trabalhadores. Entre esses empreendimentos, destacou-se uma cooperativa de construção civil, por sua consolidação enquanto um empreendimento solidário "que deu certo", bem como por ser um setor importante para a economia da região em que foi realizado o estudo.

É importante destacar que, historicamente, a construção civil tem desempenhado um papel estratégico para o conjunto da economia brasileira, tento em vista a absorção de grande contingente da força de trabalho migrante e/ou excedente no mercado de trabalho formal, como mostram os estudos de Lima Júnior, López-Valcárcel e Dias (2005). Por outro lado, esse setor também é reconhecido pelo trabalho precário em função de características como a informalidade dos contratos de trabalho e de o mesmo ser realizado ainda de forma muito artesanal no Brasil (GOMES, 2011).

Dados do Anuário Estatístico da Previdência Social (BRASIL, 2009) apontam que o setor da construção civil apresenta sérios problemas no campo da saúde e da segurança do trabalhador. Segundo o referido documento, no ano de 2009 foram registrados aproximadamente $54 \mathrm{mil}$ acidentes de trabalho, fazendo deste setor de atividade econômica o segundo colocado no ranking de acidentes de trabalho no Brasil. Os dados revelam também altos

A informação advém do banco de dados do Sistema Nacional de Economia Solidária - SIES (2013), disponível em http://sies.ecosol.org.br/atlas , a partir de correlações entre as variáveis criadas pelo SIES. índices de doenças do trabalho e a negligência no cumprimento da legislação, especialmente as Normas Regulamentadoras (NRs), como indica o estudo de Gomes (2011). Além de seus aspectos físicos, estudos como o de Barros e Mendes (2003) e Borsói (2007) têm apontado também para a necessidade de considerar os aspectos subjetivos da saúde do trabalhador da construção civil, avaliando os riscos psicossociais desta ocupação.

A partir do contexto apresentado, este estudo teve como objetivo analisar as vivências de prazer e sofrimento no trabalho em trabalhadores da construção civil inseridos em um empreendimento de Economia Solidária. Para tanto, buscou-se descrever como era o processo de organização do trabalho na cooperativa; delinear quais princípios da ES se faziam presentes nessa organização; e identificar as estratégias de mediação do sofrimento nesse grupo de trabalhadores.

Para atender aos objetivos propostos, utilizou-se o referencial teórico da Psicodinâmica do Trabalho, perspectiva que compreende o trabalho como central para a constituição identitária e para os processos de saúde e de doença, sempre associados ao binômio prazer-sofrimento. Nesta perspectiva, a saúde do trabalhador é compreendida como "[...] expressão de um estado disposicional caracterizado pelo equilíbrio marcado pela vivência de prazer e sofrimento, e pela utilização de mecanismos capazes de mobilizar os trabalhadores em busca de uma relação mais gratificante no trabalho" (MENDES, 2007, p. 46). Assim, pensar a saúde de modo articulado ao trabalho no empreendimento em questão remete considerar a relação entre a subjetividade do trabalhador, o seu saber/ fazer e o coletivo de trabalho.

\section{Encaminhamentos metodológicos}

Este estudo foi realizado a partir da perspectiva da pesquisa qualitativa, como base nos pressupostos de González-Rey (1997). Como já assinalado, fez-se a opção pela psicodinâmica do trabalho para analisar as vivências de prazer e sofrimento em trabalhadores da construção civil inseridos em um empreendimento de Economia Solidária. No entanto, essa abordagem foi utilizada apenas como categoria teórica, e não no método originalmente proposto por Dejours, acompanhando a tendência dos trabalhados brasileiros como destacam Merlo e Mendes (2009).

No momento da pesquisa, a cooperativa contava com 48 sócios, dos quais 24 estavam ativos na atividade da construção civil, sendo que somente esses últimos participaram da pesquisa. Desse grupo de trabalhadores ativos na atividade, 23 eram do sexo masculino e um era do sexo feminino, informação que vai ao encontro dos dados apontados pelo DIEESE - Departamento Intersindical de Estatística e Estudos Socioeconômicos ${ }^{2}$ (2008) acerca do predomínio de trabalhadores do sexo masculino no setor. As idades desses trabalhadores variavam entre 21 a 56 anos e o tempo médio de trabalho no setor era de oito anos.

${ }^{2} \mathrm{~A}$ informação advém do banco de dados do DIEESE CAGED/MTE (2008), disponível em http://www.dieese.org.br, a partir de filtros aplicados.

Fractal, Rev. Psicol., v. 29 - n. 1, p. 9-16, 2017 
Foram utilizadas como técnicas de pesquisa a observação, com registro em diário de campo, grupo focal e, como instrumento de pesquisa, um questionário. A observação participante, com registro em diário de campo, foi realizada durante toda a pesquisa de campo e contou, também, com o acompanhamento de sete reuniões e uma assembleia da cooperativa. Por meio da participação nessas reuniões buscou-se conhecer a organização e funcionamento deste empreendimento, bem como alcançar uma maior aproximação com os sujeitos de pesquisa.

O questionário foi aplicado aos 24 cooperados ativos. As questões foram elaboradas com base nos campos temáticos apontados pelo Inventário de Trabalho e Riscos de Adoecimento (ITRA) que tem como base a Psicodinâmica do Trabalho (MENDES; FERREIRA, 2007). Após a fase de aplicação do questionário, foi realizado o grupo focal com todos os trabalhadores na sede da cooperativa, em dois encontros. De acordo com Weller (2006, p. 246), essa estratégia é "uma ferramenta importante para a reconstrução dos contextos sociais e dos modelos que orientam as ações do sujeito". Neste sentido, o grupo teve como objetivo discutir e refletir de modo coletivo os temas levantados inicialmente por meio do questionário, sendo eles: contexto de trabalho, exigências do trabalho, sentidos do trabalho e efeitos do trabalho para a saúde.

A análise das informações foi realizada por meio da Análise de Conteúdo, a partir da definição de González-Rey (1997), dando origem aos seguintes núcleos temáticos: vivências de prazer e princípios da ES e vivências de sofrimento e riscos à saúde. Estes núcleos nortearão as discussões feitas no presente artigo.

\section{Resultados e discussão}

\section{Os princípios da Economia Solidária possibilitando vivências de prazer no trabalho}

A cooperativa de construção civil analisada neste estudo se localiza na Região Oeste do estado de Santa Catarina. A mesma iniciou suas atividades em 2005, quando um grupo de trabalhadores(as), constituído por cerca de 30 famílias - em geral, descendentes de agricultores familiares da região -, reuniram-se para criar uma organização que favorecesse melhores condições de trabalho e renda.

O cenário regional que marcou essa iniciativa é resultado do processo de modernização agrícola e do êxodo rural que iniciou na década de 1970, ao qual Testa et al. (1996) denominaram "modernização dolorosa". Este cenário foi caracterizado pela dificuldade de acesso aos novos modos de produção, gerando exclusão e empobrecimento dos agricultores familiares, os quais representavam, na época, cerca de $90 \%$ dos estabelecimentos agrícolas da região.

Embora os índices de crescimento populacional urbano tenham aumentado consideravelmente na época, o desenvolvimento social e econômico não cresceu na mesma proporção, ocasionando o aumento do desemprego, que ampliou as precárias condições de vida da população. Este cenário deu origem, na região, a diversas lutas sociais, protagonizadas por movimentos sociais, sindicatos, lideranças religiosas entre outros, que abriram caminhos para a formação de novos projetos e para experiências de organização e expressão popular.

Fruto desse processo, a cooperativa foi constituída por adeptos e militantes dos movimentos sociais da região, tais como o Movimento dos Sem Terra (MST), Movimento dos Atingidos por Barragens (MAB) e Movimento das Mulheres Camponesas (MMC). Em sua maioria, os cooperados eram pessoas que, naquele momento, estavam desempregadas ou eram assalariados das grandes empresas imobiliárias e de construção civil da cidade, recebendo, segundo seus relatos, baixos salários. Frente a essa realidade, a constituição do empreendimento em análise realiza o papel que Singer (2002) delega à ES na luta contra as desigualdades sociais e o desemprego, condições que, de acordo com Dejours (2007), levam ao consentimento para participar do sistema e ao sofrimento pelas condições de trabalho que esse oferece.

Cabe destacar que, desde sua constituição, esse empreendimento sempre esteve articulado à rede de Economia Solidária por intermédio da participação em fóruns e seminários, bem como da articulação com a ITCP. Essas experiências também favoreceram a formação política dos cooperados e a capacitação de lideranças no empreendimento. Assim, a trajetória de constituição e de desenvolvimento desta cooperativa confere-lhe um modelo diferenciado de gestão, que facilita a aproximação deste empreendimento aos princípios da ES.

Além disso, o índice de analfabetismo dos trabalhadores é zero, predominando a formação no ensino médio (11 trabalhadores), seguido de ensino fundamental (nove trabalhadores) e ensino superior (três associados). Tais dados se contrapõem ao elevado índice de analfabetismo e baixa escolaridade na construção civil, registrado pelo DIEESE (2008).

Verificou-se, ainda, que parte da carga horária laboral é destinada à realização de atividades formativas como reuniões, cursos e capacitações. Tal aspecto revela a preocupação da cooperativa com a educação permanente de seus associados, aspecto intrinsecamente voltado aos princípios da ES. Nesse sentido, a educação, seja por meio da escolarização formal, seja através das capacitações promovidas pelo empreendimento e pela rede de $\mathrm{ES}$, cumpre um dos princípios do cooperativismo inserido no movimento de ES. Por meio dessa formação qualifica-se a participação dos trabalhadores nos espaços de discussão presentes no empreendimento, colocando o sujeito como principal finalidade da atividade econômica.

Outro aspecto que diferencia o empreendimento diz respeito à remuneração dos trabalhadores cooperados. Nesse sentido, dados da CBIC - Câmara Brasileira da Indústria da Construção (2002) ${ }^{3}$ apontam que os trabalhadores do setor da construção civil no Brasil recebem baixos salários e muitas vezes não tem sua atividade registrada na carteira de trabalho, ficando à margem dos direitos trabalhistas, aspectos também apontados no estudo de Gomes (2011).

${ }^{3} \mathrm{~A}$ informação advém do banco de dados da CBIC (2008), disponível em http:// www.cbicdados.com.br/home/, a partir de filtros aplicados. 
Em contrapartida, segundo o relato dos trabalhadores, a cooperativa estudada tem conseguido manter ou até superar a média dos valores pagos aos trabalhadores da construção civil na região. ${ }^{4}$ Todos os trabalhadores são contribuintes da previdência social, usufruem anualmente do que denominam de "fundo de final de ano" (semelhante ao $13^{\circ}$ salário) e de férias. Possuem, ainda, seguro de vida e plano de saúde. Tais características do trabalho, só são possíveis por meio da propriedade coletiva e distribuição equitativa dos resultados do trabalho, aspectos que marcam esse tipo de empreendimento como indica Singer (2002) e que ao configurar uma retribuição material pela dedicação ao trabalho, caracterizam uma dimensão do reconhecimento deste, o que é mobilizador de prazer (MENDES, 2008).

A estabilidade laboral e financeira que a condição citada anteriormente possibilita, também favorece a ausência de medo e insegurança, tão característicos em ambientes de trabalho precarizados e que geram sofrimento, como assinala Dejours (2007). Assim, nos resultados do questionário, observamos que 21 trabalhadores afirmaram "nunca" ou "raramente" se sentirem inseguros e 19 não terem vivenciado o medo em relação ao seu ambiente de trabalho.

Quanto à organização do trabalho, observamos reduzida divisão técnica e social do trabalho, pois, como diz Pedro, "todos sabem e fazem um pouco de tudo", desenvolvendo diferentes atividades, como acabamento, assentamento de tijolo, cerâmica, gesso, eletrificação, pintura etc. Este aspecto contribui para que as tarefas executadas não sejam compreendidas pelos trabalhadores como descontínuas, já que o grupo de cooperados acompanha todas as fases da obra, desde a aprovação da execução, o desenho do projeto, até a quantidade e tipo dos materiais necessários.

A aproximação entre planejamento e execução do trabalho é possível por meio da realização do princípio do controle democrático por parte dos membros que se dá especialmente por meio das discussões coletivas, como aponta João: "O fato de todos poderem participar das reuniões, ter voz e vez, faz com que tenham a oportunidade de planejar juntos as tarefas, não tendo esta divisão". A maior participação do trabalhador possibilitada pelos espaços públicos de fala, no sentido apontado por Dejours (1999), contribui para a integração dos diferentes conhecimentos no processo de trabalho e cria possibilidade de negociação.

Apesar da possibilidade de negociação, o trabalho na cooperativa segue regras e normas estabelecidas para o mesmo. De acordo com o presidente da Cooperativa, a norma se refere a "toda regra necessária ao desenvolvimento do trabalho. O que é para ser cumprido para garantir o melhor desempenho, o resultado final do serviço de forma igual para todos, o padrão de qualidade".

\footnotetext{
${ }^{4}$ Segundo uma das lideranças, o valor pago aos trabalhadores da construção civil, na região na qual se encontra localizada a cooperativa, é de 1,5 salário mínimo mensal. Considerar o valor referente a maio de 2010.

${ }^{5}$ Com vistas a preservar a identificação dos participantes, os nomes usados serão fictícios.
}

Nesse sentido, cabe destacar que apesar das rupturas que o empreendimento faz em relação aos modos tradicionais de organização do trabalho, o fato de estar inserido em um sistema capitalista o submete a algumas exigências do mercado.

No entanto, é importante destacar que as regras e normas no empreendimento foram discutidas e definidas pelo grupo de trabalhadores cooperados e que essas são passíveis de negociação no coletivo. Este aspecto parece ser essencial para a manutenção do empreendimento, como mostra a fala de Matias: "Todo trabalho, mais ainda na construção civil, precisa seguir uma norma, regra, mas eu acredito que não há uma rigidez, pois, o modo como você usa desta regra depende de cada um; a norma não inibe a autonomia".

A possibilidade de modificar as normas impostas pelo coletivo também é ressaltada na fala de outro cooperado quando esse diz:

Você não vai fazer uma parede de tijolos sem assentar com o cimento porque vai cair tudo. Então é uma regra do bom senso. Mas se você provar que dá certo, que a tua experiência diz que não vai desmoronar e a maioria concordar, nós mudamos a norma.

A partir das falas dos sujeitos, pode-se afirmar que a forma de organização do trabalho possibilitada pela cooperativa, preserva certa autonomia do trabalhador. Essa, por sua vez, é uma mobilizadora de prazer, como afirmam Moraes, Vasconcelos e Cunha (2012) e ao favorecer, por meio do emprego da inteligência prática, a criação de estratégias de enfrentamento ao sofrimento do trabalho (DEJOURS, 2008). Assim, o sujeito pode criar formas mais eficazes de realizar suas atividades.

Já a definição coletiva das normas, em que são socializadas e discutidas as melhores formas de realizar o trabalho, favorece que a inteligência prática transforme-se em sabedoria prática (DEJOURS, 2008). Esse modo de trabalho também vai ao encontro dos valores centrais da Economia Solidária como o saber e a criatividade humana, em que o sujeito é finalidade da atividade econômica, em vez da acumulação privada de riqueza, em geral, e de capital, em particular.

Além das reuniões que acontecem semanalmente, a cooperativa promove momentos festivos (festas de aniversário, Dia do Trabalhador, Fim de Ano, Natal etc.), viagens de estudo, de lazer e assembleias anuais, os quais são avaliados pelos cooperados como ocasiões de grande importância para integração, planejamento, acompanhamento e avaliação do trabalho, bem como para os redimensionamentos necessários aos processos de trabalho. Assim, esses momentos possibilitam relações de trabalho diferenciadas, ao favorecer relações de confiança, cooperação e a criação de espaços públicos de fala, os quais também se caracterizam como elementos fundamentais para a transformação do sofrimento e as vivências de prazer (MENDES; MORRONE, 2010).

Os momentos acima citados facilitam a comunicação no contexto de trabalho, sendo que o resultado de uma das questões do questionário revela que, para a grande

Fractal, Rev. Psicol., v. 29 - n. 1, p. 9-16, 2017 
maioria (22 participantes), as tarefas estão claramente definidas, o que facilita sua execução. Tal aspecto tem estreita relação com a facilidade de encontrar as informações que precisam para desenvolver o trabalho, mencionada por 20 participantes. De acordo com os cooperados, as informações e as dúvidas são geralmente esclarecidas nos momentos de reuniões, sejam elas no coletivo maior, sejam elas nas sub-equipes de trabalhos.

Outro efeito desses espaços públicos de fala é que a fiscalização de desempenho não se torna uma prática autoritária e intimidadora, mas uma ação em que todos têm a responsabilidade de "acompanhar, olhar como as coisas estão indo, querer saber do trabalho", como destaca Jorge. Nesse sentido, Mendes (2008) salienta que é por meio da construção de espaços que mobilizam os trabalhadores à condição de fala-escuta que "se opera o processo de contribuição-retribuição simbólica, condição essencial para o reconhecimento, o prazer e a ação sobre a organização do trabalho" (MENDES, 2008, p. 15). Estudos como os de Ghizoni (2013) e Ghizoni e Mendes (2014) vão ao encontro desta observação, ao evidenciar como uma escuta qualificada ao sentimento dos trabalhadores, possibilita a ressignificação do sofrimento vivenciado no ambiente laboral.

Contudo, vale ressaltar a fala de um dos cooperados, salientando que poder falar o que pensa, opinar, não significa necessariamente transformar suas ideias em ações da gestão na cooperativa, fato que acaba confundindo "poder participar" com "tem que ser a minha ideia". Para o cooperado Matias, "não ter minha ideia aceita no coletivo" pode representar uma forma de discriminação no grupo. Nessa direção, Dejours (1999) aponta que a construção dos espaços de circulação da palavra coletiva diz respeito a um processo complexo, que pode compreender inúmeros confrontos, pois o uso da palavra, tanto para quem fala quanto para quem ouve, implica riscos de não se fazer compreender e de não ser capaz de compreender o outro, contribuindo para vivências de sofrimento. Assim, esses processos somente se sustentam se houver o reconhecimento.

As discussões realizadas pelo grupo pesquisado apontaram que esse reconhecimento se dá por meio de elogios recebidos dos colegas pelo trabalho bem feito, pela demonstração de que o trabalho é útil à cooperativa e pelo respeito à opinião de cada cooperado. O prazer, na condição de um princípio mobilizador, envolve o trabalhador no movimento de vivenciar a gratificação, a realização de si, no contexto do trabalho, e situações em que seu trabalho seja reconhecido pela sua utilidade e pela sua beleza (MENDES; MULLER, 2013).

Especialmente para as pessoas com idade acima da média geral dos cooperados (37 anos), o reconhecimento apareceu representado pelo respeito a sua experiência profissional, ao modo de fazer, pelo envolvimento afetivo do grupo, fazendo-os se sentir parte deste. Assim, destaca-se que a prática da autogestão possibilita a transformação do sofrimento do trabalho, pois suscita "[...]

Fractal, Rev. Psicol., v. 29 - n. 1, p. 9-16, 2017 solidariedade no lugar da concorrência, convergência de esforços no lugar da competição destrutiva, cooperação no lugar do individualismo" (VERARDO, 2005, p. 24).

A apropriação dos princípios da ES na organização do trabalho mobiliza o cooperado quando este se engaja, se apropria, negocia ou mesmo rejeita as regras do coletivo, contribuindo para a construção da identidade no trabalho. Estudos ${ }^{6}$ apontam que a mesma se produz pela interação dialética do "eu" - indivíduo com o "outro" - coletivo, sendo mediada pelas representações e significações socialmente construídas. Desse modo, o trabalhador procura imprimir sua marca pessoal, seus desejos, seus sonhos e seus objetivos ao processo de trabalho, (re)construindo constantemente sua subjetividade e reconciliando o trabalhador com os meios de produção.

Apesar da prática da Economia Solidária favorecer a transformação do sofrimento e as vivências de prazer dos trabalhadores, as condições de trabalho características da construção civil imprimem modos de sofrimento que persistem nesses contextos produtivos.

\section{Vivências de sofrimento: os riscos do trabalho na construção civil e necessidade de ser competitivo}

O trabalho na construção civil no Brasil é marcado por longas jornadas de trabalho, precárias condições evidenciadas por situações laborais adversas e insalubres e elevado índice de acidentes (BRASIL, 2009; GOMES, 2011; PARENTI, 1999; SERVIÇO SOCIAL DA INDÚSTRIA [SESI], 1998; SOUZA, 1999). Estes aspectos favorecem a prevalência do medo de se acidentar, de morrer, de perder o emprego, de estresse, de insegurança e de desgaste físico nesta categoria ocupacional.

As vivências de sofrimento mais preponderantes no contexto de trabalho da cooperativa pesquisada estão relacionadas aos danos físicos ocasionados pelo trabalho. Nesse sentido, aponta o cooperado Tadeu: "Eu fui trabalhador de indústria, não dá para comparar, você sai de lá meio zonzo. Acho que o jeito que a gente trabalha aqui ajuda a mente, favorece a saúde. O único problema é o trabalhar no pesado".

Esta condição está relacionada às características do trabalho na construção civil, em que atividades como carregar materiais pesados ou manter-se numa mesma posição por muito tempo fazem parte da rotina de trabalho. Nesse sentido, Gomes (2011) aponta que no Brasil o trabalho na construção civil ainda é realizado de forma predominantemente artesanal, especialmente nas empresas menores como é o caso da cooperativa em questão, em que se prioriza o trabalho braçal em detrimento do uso de outras tecnologias.

O trabalho realizado, de acordo com os cooperados, está relacionado assim, à ocorrência frequente de dores nas costas, mencionadas por todos os trabalhadores participantes do estudo. Também predominam dores nas pernas, mencionadas por oito trabalhadores, e dores nos braços e no corpo, mencionadas por onze trabalhadores. No entanto, a presença de rodízio na realização das ati-

${ }^{6}$ Codo e Sampaio (1995), Cruz (2001, 2004), Dejours (1980), Mendes (2007). 
vidades, funciona como um fator que ameniza os riscos laborais e diferencia o trabalho na cooperativa de outras empresas do setor. Como diz o cooperado João: "Nem tem comparação com a empresa! Porque lá, eu sei, fica o dia todo, mês, ano, fazendo a mesma coisa, no mesmo lugar".

A percepção dos riscos inerentes à atividade da construção civil é outro aspecto que pode ser relacionado ao sofrimento do trabalhador deste setor. Em resposta ao questionário, dez cooperados reconhecem que existem riscos à segurança dos trabalhadores nesta ocupação. Essa percepção é corroborada pelos acidentes de trabalho que acontecem na cooperativa. Nesse sentido, um acidente de trabalho com um cooperado devido a uma queda em uma obra ocasionou a fratura de sua coluna cervical, levando-o à incapacidade laboral permanente. Durante o período dessa pesquisa, dois outros trabalhadores precisaram afastar-se temporariamente do trabalho em função de acidentes de trabalho típicos.

De acordo com as questões levantadas no grupo de discussão, todos os trabalhadores têm acesso aos Equipamentos de Proteção Individual (EPI), não tendo dificuldades em seu uso e seu manuseio. Contudo, alguns cooperados assumem que mesmo com o uso dos EPIs vários riscos laborais permanecem. A menção de que os EPIs não protegem o trabalhador de todos os riscos pode ser relacionada ao que apontam Takahashi et al. (2012) sobre os procedimentos de segurança na construção civil representarem um modelo ideal de trabalho que não vai ao encontro das condições reais para realização do mesmo no setor. Nesse sentido, aponta um trabalhador: "Mas também se a gente ficar preso no risco ninguém trabalha. Claro que a construção está mais sujeita aos acidentes, mas é nosso trabalho. Então, tem que desencanar um pouco, mas claro, usar os equipamentos direitinho".

A fala do trabalhador anteriormente citada vai ao encontro do que menciona Takahashi et al. (2012, p. 979) de na construção civil torna-se "[...] impossível prever, de antemão, todas as eventualidades do trabalho, a multiplicidade das ocorrências e a proliferação de microdetalhes cuja formalização implicaria num enorme e complexo labirinto de modos operatórios possíveis". Nesse sentido, se observa que os EPIs são projetados para atender o trabalho prescrito, que diverge do trabalho real no setor.

Apesar do acesso aos EPIs e da fala de que o uso dos mesmos não representa uma dificuldade para realização do trabalho, as lideranças do empreendimento mencionam a resistência dos trabalhadores em usar esses equipamentos. Nesse sentido, Pedro diz que a segurança no trabalho "[...] depende da consciência de cada um quanto à importância de cumprir as normas". Já para Carlos: "As pessoas vem cheias de vícios para a Cooperativa, não usam para se proteger, mas para evitar multa, que é a visão da empresa".

De acordo com Dejours (1980), de uma forma geral existem, em alguns tipos de ofício, sinais indiretos do medo que são passíveis de gerar uma ideologia ocupacional defensiva. Na construção civil os perigos têm um peso real, entretanto, muitos trabalhadores apresentam resistência em seguir as normas de segurança. Segundo o autor anteriormente referido, esses comportamentos podem estar relacionados a valores ligados à virilidade, à bravura, sendo representados por uma conduta que visa suportar justamente um risco que não seria completamente amenizado por medidas de segurança. A negação do risco por meio da recusa em utilizar os EPIs seria, assim, uma estratégia defensiva com um valor funcional em relação ao grupo, sua coesão, sua coragem, sendo também garantia da produtividade.

A necessidade de garantir a produtividade, também emerge no grupo de discussão como estando relacionada às manifestações de sofrimento em função da necessidade de ter controle das emoções e das opiniões. Nesse sentido, os trabalhadores mostraram que, muitas vezes, se sentem obrigados a disfarçar sentimentos como destaca o presidente da cooperativa quando diz: "Às vezes a gente tem que se segurar na frente do cliente, quando ele oferece pouco pelo serviço, atrasa no pagamento".

Assim, observamos que mesmo ocorrendo rupturas do empreendimento com modos de organização do trabalho capitalistas, estas possuem limites impostos pela necessidade de se inserir e de competir na lógica do mercado, provocando algumas contradições no contexto de trabalho. Isso se evidenciou também quando os cooperados avaliaram as dificuldades relativas ao trabalho, em que destacaram as pressões e cobranças dos clientes pelo cumprimento de prazos.

Relacionados às questões anterior, ocorrem vivências de sofrimento marcadas pelo sentimento de esgotamento emocional e frustração, representados pelas respostas de 16 trabalhadores. No entanto, ao discutirem sobre a presença desses sentimentos, os mesmos foram considerados pelos trabalhadores como algo "natural", que "faz parte" do processo organizativo, pois as cobranças e pressões do cliente são vistas como inerentes ao trabalho na construção civil.

Assim, a cobrança do cliente também produz cobrança entre os cooperados, como pode ser observado na fala do cooperado Felipe:

A cobrança tem que fazer parte da organização do trabalho, não de forma exagerada. Mas ela é necessária para o crescimento da cooperativa, ajuda a manter a produção, a qualidade. Por que se tem uma obra a gente pensou e viu que dava para pegar, então tem que um cobrar do outro e cada um de si para dar o melhor para cumprir aquilo. Não tem só um que cobra, é todo mundo de todo mundo.

Pode-se afirmar que a naturalização dos sentimentos que cercam a cobrança pelo cumprimento de prazos se constitui, como uma estratégia defensiva no sentido apontado por Dejours (1980), em que ao não ser possível alterar a realidade, busca-se minimizar a percepção da mesma na medida em que ela gera sofrimento. Ao utilizar essa estratégia defensiva, os trabalhadores, mesmo sem perceber, tendem a manter o comportamento mais adequado e exigido pelo mercado de trabalho, submetendo- 
-se ao desejo da excelência e da produtividade, os quais são necessários para que a cooperativa possa competir com outras empresas do ramo da construção civil.

\section{Considerações finais}

Este estudo teve como objetivo analisar as vivências de prazer e sofrimento no trabalho em operários da construção civil inseridos em um empreendimento de Economia Solidária. Nesse sentido, observou-se na organização do trabalho a forte presença de princípios da Economia Solidária, bem como do cooperativismo que compõe o movimento desta que pretende se colocar como uma nova forma de economia.

Entre esses princípios se destacou a solidariedade na realização do trabalho em detrimento da competição e individualismo. Nesse sentido, os modos de trabalho presentes na cooperativa possibilitam a constituição de relações socioprofissionais positivas, em que ocorre o apoio mútuo entre os trabalhadores, possibilitando relações diversas daquelas estimuladas pelos modos de trabalho contemporâneo.

A presença do princípio da igualdade nas relações entre os sócios se dá em conjunto com o do controle democrático. Esses são possíveis especialmente por meio dos diversos espaços públicos de fala que existem no contexto do empreendimento, em que são discutidas e definidas as normas e regras de modo coletivo. Nesse sentido, se de um lado é audacioso, pelas limitações da pesquisa, afirmar a existência da autogestão, de outro, não se pode negar a vivência de co-responsabilidades, domínio do processo produtivo, liberdade de expressão, respeito ao saber e a criatividade como elementos constituintes das relações socioprofissionais que se estabelecem neste contexto.

Já o compromisso com a educação dos membros da cooperativa se expressa, além do alto nível de escolaridade dos cooperados se comparado aos trabalhadores desse setor, pela participação em espaços de formação técnica e política. Entre esses estão Fóruns, Congressos, encontros de redes de empreendimentos solidários.

A cooperativa também cumpre um papel importante no sentido garantir aos cooperados a geração de trabalho e renda e um trabalho menos precarizado, se comparado os resultados de outras pesquisas com trabalhadores do setor da construção civil. Assim, a partir dos resultados dessa pesquisa se pode observar que o trabalho regido pelos princípios da Economia Solidária favorece a construção de estratégias de enfrentamento das adversidades dos contextos de trabalho contemporâneos e à transformação do sofrimento do trabalhador. Os empreendimentos solidários são, nesse contexto, uma oportunidade para o trabalho vivo, por meio da ação política e da experiência com o real que permitem ao trabalhador agir sobre a organização do trabalho, favorecendo as vivências de prazer e a saúde.

Apesar dos aspectos positivos, emergem também nesse contexto, vivências de sofrimento, especialmente relacionadas aos riscos do trabalho e aos danos físicos ocasionados por esses. Assim, antigos problemas do se- tor da construção civil se reproduzem nesse contexto, como a presença de acidentes de trabalho, recusa no uso de EPIs e estratégias defensivas para negar os riscos.

Outras manifestações de sofrimento estão associadas à necessidade do empreendimento se inserir e competir na lógica de mercado, o que expõe os trabalhadores a necessidade de cumprir prazos, realizar o controle de qualidade do serviço e ter que controlar as emoções. Aqui vale destacar a impossibilidade de esses empreendimentos oferecerem um trabalho plenamente humanizado e autônomo, dentro do contexto da economia capitalista.

No sentido destacado anteriormente, a presença dos princípios da ES se mostrou muito limitada ao contexto interno do empreendimento, sem evidenciar suas possibilidades e limites junto ao movimento da ES, o que também caracterizou um limite desse estudo. Como pauta de trabalhos futuros sugere-se investigar a realização desses princípios de forma mais ampla, e sua relação com as vivências de prazer e sofrimento dos trabalhadores; fazer estudos multicasos em que se relacione o contexto de trabalho nos empreendimentos de ES com outras empresas de construção civil, bem como com outras cooperativas de ES de setores distintos, a fim de identificar diferentes estratégias de mediação do sofrimento nesses empreendimentos; ainda, estudar o potencial da Psicodinâmica do Trabalho, enquanto pressuposto teórico e metodológico, ao enfrentamento de riscos e danos à saúde mental dos trabalhadores do setor da construção civil, bem como no contexto da ES.

\section{Referências}

BARROS, P. C. R.; MENDES, A. M. Sofrimento psíquico no trabalho e estratégias defensivas dos operários terceirizados da construção civil. Psico-USF, Itatiba, v. 8, n.1, p 63-70, jan./jun. 2003. Cross ${ }^{\text {Ref. }}$

BORSÓI, I. C. F. Da relação entre trabalho e saúde á relação entre trabalho e saúde mental. Psicologia \& Sociedade, Porto Alegre, v.19, n. spe., p. 103-111, 2007. Cross ${ }^{\text {Ref. }}$

BRASIL, Ministério da Previdência Social. Anuário Estatístico da Previdência Social 2009. Brasília, DF, 2009. Disponível em: <http://www.previdencia.gov.br/conteudoDinamico. php?id=990>. Acesso em: $10 \mathrm{dez} .2010$.

BRASIL. Ministério do Trabalho e do Emprego. Secretaria Nacional de Economia Solidária. Sistema Nacional de Informações em Economia Solidária - SIES. Atlas Digital de Economia Solidária. Brasília, DF: MTE/SENAES, 2013. Disponível em: <http://sies.ecosol.org.br/atlas> . Acesso em: 20 abr.2017.

CÂMARA BRASILERIA DA INDÚSTRIA DA CONSTRUÇÃO. Banco de dados. Belo Horizonte: Comissão de Economia e Estatística - CEE/CBIC, 2002. Disponível em: $<$ http://www.cbicdados.com.br/home/>. Acesso em: 15 set. 2010.

CODO, W.; SAMPAIO, J. (Org.). Sofrimento psíquico nas organizações: saúde mental e trabalho. Petrópolis, RJ: Vozes, 1995.

CRUZ, R. M. Psicodiagnóstico de síndromes dolorosas crônicas relacionadas ao trabalho. 2001. Tese (Doutorado)Universidade Federal de Santa Catarina, Santa Catarina, 2001. 
CRUZ, R. M. Distúrbios musculoesqueléticos, processos de trabalho e cultura organizacional. In: TAMAIO, A. (Org.). Cultura e saúde nas organizações. Porto Alegre: Artmed, 2004. p. 231-252.

DEJOURS, C. A loucura do trabalho: estudo de psicopatologia do trabalho. São Paulo: Cortez-Oboré, 1980.

DEJOURS, C. Conferências Brasileiras. São Paulo: FUNDAP, EAESP/FGV, 1999.

DEJOURS, C. A banalização da injustiça social. 7. ed. Rio de Janeiro: FGV, 2007.

DEJOURS, C. Novas formas de servidão e de suicídio. In: MENDES, A. M. Trabalho \& saúde: o sujeito entre a emancipação e a servidão. Curitiba: Juruá, 2008. p. 26-39.

DEPARTAMENTO INTERSINDICAL DE ESTATÍSTICA E ESTUDOS SOCIOECONÔMICOS - DIEESE. Anuário dos Trabalhadores. 9. ed. Brasília, 2008. Disponível em: $<$ http://www.dieese.org.br/anuario/2008/anuario trabalhadores_2008.pdf>. Acesso em: $10 \mathrm{dez} .2010$.

GHIZONI, L. D. Clínica psicodinâmica da cooperação na Associação de Catadores e Catadoras de Materiais Recicláveis da Região Centro Norte de Palmas - TO (ASCAMPA). 2013. Tese (Doutorado em Psicologia Social, do Trabalho e das Organizações [PSTO])-Universidade de Brasília, Brasília, 2013

GHIZONI, L. D.; MENDES, A. M. Dispositivos para uma escuta clínica do sofrimento no trabalho dos catadores de materiais recicláveis. Contextos Clínicos, São Leopoldo, v. 7, n. 1. p. 15-26, jan./jun. 2014. Cross ${ }^{\text {Ref. }}$

GOMES, H. P. Construção civil e saúde do trabalhador: um olhar sobre as pequenas obras. 2011. Tese (Doutorado)-Escola Nacional de Saúde Pública Sérgio Arouca - FIOCRUZ, Rio de Janeiro, 2011.

GONZÁLEZ-REY, F. L. Epistemología Cualitativa y Subjetividade. São Paulo: EDUC, 1997.

KARAM, H. Centralidade do trabalho e saúde mental pública. In: MENDES, A. M. (Org.). Trabalho \& saúde: o sujeito ente a emancipação e a servidão. Curitiba: Juruá, 2008. p. 139-152.

MENDES, A. M. Psicodinâmica do trabalho: teoria, métodos e pesquisas. São Paulo: Casa do Psicólogo, 2007.

MENDES, A. M. Prazer, reconhecimento e transformação do sofrimento no trabalho. In: MENDES, A. M. Trabalho \& saúde: o sujeito entre a emancipação e a servidão. Curitiba: Juruá, 2008. p. 13-25.

MENDES, A. M.; FERREIRA, M. C. Inventário sobre o Trabalho e Riscos de Adoecimento - ITRA: instrumento auxiliar de diagnóstico de indicadores críticos no trabalho. In: MENDES, A. M. (Org.). Psicodinâmica do Trabalho: teoria, método e pesquisas. São Paulo: Casa do Psicólogo, 2007. p. 111-126.

MENDES, A. M.; MORRONE, C. F. Trajetória teórica e pesquisas brasileiras sobre prazer e sofrimento no trabalho. In: MENDES, A. M. et al. (Org.). Psicodinâmica e clínica do trabalho: temas, interfaces e casos brasileiros. Curitiba: Juruá, 2010. p. 29-52.

MENDES, A. M.; MULLER, T. C. Prazer no trabalho. In: VIEIRA, F. O.; MENDES, A. M.; MERLO, A. R. C. (Org.). Dicionário crítico de gestão e psicodinâmica do trabalho. Curitiba: Juruá, 2013. p. 289-292.

MERLO, A. R. C.; MENDES, A. M. Perspectivas do uso da psicodinâmica do trabalho no Brasil: teoria, pesquisa e ação. Cadernos de Psicologia Social do Trabalho, São Paulo, v. 12, n. 2, p. 141-156, dez. 2009. Cross ${ }^{\text {Ref. }}$
MORAES, R. D.; VASCONCELOS, A. C. L.; CUNHA, S. C. P. Prazer no trabalho: O lugar da autonomia. Psicologia, Organizações e Trabalho, Florianópolis, v. 12, n. 2, p. 217-228, ago. 2012. Disponível em: <http://pepsic.bvsalud.org/scielo. php?script=sci_arttext\&pid=S1984-66572012000200007\&lng $=$ pt\&nrm=iso>. Acesso em: 2 ago. 2013.

LIMA JÚNIOR, J. M.; LÓPEZ-VALCÁRCEL, A.; DIAS, L. A. Segurança e saúde no trabalho da construção: experiência brasileira e panorama internacional. Brasília: OIT, 2005.

PARENTI, M. G. F. Trabalhadores da construção civil e a experiência escolar: significados construídos em um curso de aperfeiçoamento profissional. 1999. Dissertação (Mestrado)Universidade Federal de Minas Gerais, Minas Gerais, 1999.

QUIJANO, A. Sistemas alternativos de produção? In: SANTOS, B. de S. (Org.). Produzir para viver: os caminhos da produção não capitalista. Rio de Janeiro: Civilização Brasileira, 2002. p. 475-512.

SANTOS, B. S.; RODRIGUEZ, C. Para ampliar o cânone da produção. In: SANTOS, B. S. (Org.). Produzir para viver: os caminhos da produção não capitalista. Rio de Janeiro: Civilização Brasileira, 2002, p. 23-77.

SERVIÇO SOCIAL DA INDÚSTRIA. Diagnóstico da mãode-obra do setor da construção civil no Brasil. Brasília: SESIDF, 1998.

SILVA, M. L. L. Previdência social no Brasil: (des)estruturação do trabalho e condições para sua universalização. São Paulo: Cortez, 2012.

SINGER, P. Introdução à economia solidária. São Paulo: Fundação Perseu Abramo, 2002.

SOUZA, N. H. B. de. Gestão do trabalho na indústria da construção civil: práticas tradicionais e perspectivas futuras. Revista Ser Social, Brasília, v. 5, n. 9, p. 159-188, 1999.

TESTA, V. M. et al. O desenvolvimento sustentável do Oeste Catarinense: proposta para discussão. Florianópolis: EPAGRI, 1996.

VERARDO, L. Construindo autogestão e parceria solidária. In: MELLO, S. L. (Org.). Economia solidária e autogestão: encontros internacionais. São Paulo: NESOL-USP, ITCP-USP, PW, 2005. p. 119-127.

TAKAHASHI, M. A. B. C. et al. Precarização do trabalho e risco de acidentes na construção civil: um estudo com base na Análise Coletiva do Trabalho (ACT). Saúde e Sociedade, São Paulo, v. 21, n. 4, p. 976-988, out./dez., 2012. Cross ${ }^{\text {Ref. }}$

TODESCHINI, R.; LINO, D. A importância social do Ntep e a busca de integração das políticas públicas de segurança e saúde do trabalhador. In: MACHADO, J.; SORATTO, L.; CODO, W. Saúde e trabalho no Brasil: uma revolução silenciosa. Petrópolis, RJ: Vozes, 2010. p. 23-35.

WELLER, W. Grupo de discussão na pesquisa com adolescentes e jovens: aportes teóricos-metodológicos e análise de uma experiência com o método. Educação e Pesquisa, São Paulo, v. 32, n. 2, p. 241-260, maio/ago. 2006. Cross ${ }^{\text {Ref. }}$

Recebido em: 9 de agosto de 2013 Aceito em: 24 de março de 2017 